\title{
Workload Control in Dual Resource Constrained High-Variety Shops: An Assessment by Simulation
}

Matthias Thürer (corresponding author), Mark Stevenson, and Paolo Renna

\begin{tabular}{|c|c|}
\hline Name: & Prof. Matthias Thürer \\
\hline Institution: & Jinan University \\
\hline \multirow[t]{4}{*}{ Address: } & Institute of Physical Internet \\
\hline & School of Electrical and Information Engineering \\
\hline & Jinan University (Zhuhai Campus) \\
\hline & 519070, Zhuhai, PR China \\
\hline E-mail: & matthiasthurer@workloadcontrol.com \\
\hline Name: & Prof. Mark Stevenson \\
\hline Institution: & Lancaster University \\
\hline \multirow[t]{4}{*}{ Address: } & Department of Management Science \\
\hline & Lancaster University Management School \\
\hline & Lancaster University \\
\hline & LA1 4YX - U.K. \\
\hline E-mail: & m.stevenson@lancaster.ac.uk \\
\hline Name: & Prof. Paolo Renna \\
\hline Institution: & Università degli Studi della Basilicata \\
\hline \multirow[t]{4}{*}{ Address: } & School of Engineering \\
\hline & Univerxità degli Studi della Basilicata \\
\hline & Via dell'Ateneo Lucano, 10 \\
\hline & 85100 Potenza - Italy \\
\hline E-mail: & paolo.renna@unibas.it \\
\hline
\end{tabular}

Keywords: Workload Control; Order Release; Worker Assignment, Job Shop; Dual Resource Constrained Shop. 


\title{
Workload Control in Dual Resource Constrained High-Variety Shops: An Assessment by Simulation
}

\begin{abstract}
Workload Control (WLC) seeks to align capacity with demand, where capacity is typically assumed to be restricted by a single constraint - machine capacity. In practice however, shops are often restricted by dual resource constraints: labor and machines. This study therefore uses simulation to investigate the performance of WLC in Dual Resource Constrained (DRC) highvariety shops with fully interchangeable labor. By considering several environmental factors and different labor assignment and dispatching rules, it is demonstrated that the order release function of WLC maintains its positive impact on performance in a DRC shop under different staffing levels. The positive effect of considering labor availability at release, as proposed in previous research, could not however be confirmed. Thus, the original release method can be applied if labor is fully interchangeable. In terms of labor assignment, we show that a distinct assignment pattern that differs between upstream and downstream stations improves performance if the routing is directed. Meanwhile, dispatching plays a less important role but creates important interaction effects with the assignment rule. Finally, the results suggest that increasing the service rate is a better response to the reduction in capacity that results from labor absenteeism than lowering the input frequency of work.
\end{abstract}

Keywords: Workload Control; Order Release; Worker Assignment, Job Shop; Dual Resource Constrained Shop. 


\section{Introduction}

This study is motivated by a major issue encountered when implementing Workload Control in make-to-order shops that produce a wide variety of products. That is, how to handle fluctuations in the supply of labor caused, for example, by attrition, a high labor turnover, or absenteeism. Most of the literature that assesses labor fluctuations focuses on the efficiency losses that occur from substituting in replacement workers (e.g. Fry et al., 1995; Slomp \& Molleman, 2002; Blumenfeld \& Inman, 2009; Bukchin \& Cohen, 2013; Nembhard, 2014). The presence of replacement workers means that a new worker is hired or surplus labor exists to ensure a 100\% (or full) staffing level is maintained. In contrast, we assume that no replacement workers are available, which leads to a situation in which capacity is constrained by two resources, i.e. machines and labor. This is typically referred to in the literature as a Dual $\underline{\text { Resource }}$ Constrained (DRC) shop (Bobrowski \& Park, 1989; Felan et al., 1993; Malhotra et al., 1993; Fredendall et al., 1996; Bokhorst et al., 2004). The assumption of no labor replacement is motivated by the limited resources typical of small companies that prohibit the creation of a 'labor buffer'. Therefore, in this paper we use controlled simulation experiments to assess the impact on Workload Control performance of adding a labor constraint, e.g. less than $100 \%$ staffing, to the standard machine capacity constraint, thus creating dual resource constraints under different labor assignment and dispatching rules.

Workload Control is a production planning and control concept specifically developed for highvariety make-to-order shops (Zäpfel \& Missbauer, 1993; Stevenson et al., 2005). It has been shown to significantly improve the performance of high-variety shops both through simulation (e.g. Thürer et al., 2012, 2014a) and, on occasions, in practice (e.g. Wiendahl, 1992; Bechte 1994; Hendry et al., 2013). A major aim of Workload Control research is to align demand (or workload) with capacity. Most Workload Control research thereby assumes that capacity is a single variable, defined by machine availability only. However, in practice most manufacturing systems are not only constrained by machines but also by labor capacity or availability (Bokhorst \& Gaalman, 2009; Stevenson et al., 2011). Machines need an operator and operators have to be assigned to machines. In addition, workers may possess different skills, levels of proficiency, or experience and therefore operate machines at different speeds. This type of highly complex shop-constrained by machines and human resources - is what we refer to as a DRC shop.

Given its practical importance, a large body of literature has emerged on the problem of DRC shops. This research typically focuses on labor assignment rules, i.e. on decisions concerning when 
to move workers to cope with a labor shortfall, where workers should be moved to, and who to move (e.g. Bobrowski \& Park, 1993; Malhotra \& Kher, 1994; Fredendall \& Melnyk, 1996; Jensen 2000; Kher, 2000a; Kher \& Fry, 2001; Bokhorst et al., 2004; Salum \& Araz, 2009; Sammarco et al., 2014). In contrast, there is very limited research on the performance impact of order release control methods in DRC shops (Bobrowski \& Park 1989; Park \& Bobrowski, 1989; Fredendall et al., 1996). Moreover, this small body of work does not consider recent advances in the order release literature and typically focuses on simple forward/backward loading based release mechanisms only.

The above means that managers that apply Workload Control order release methods in practice are not provided with any guidance on how best to handle the absence of labor or how to make release decisions in the context of multiple resource constraints. In response, this study synthesizes two streams of literature - on Workload Control and DRC shops - by assessing the performance of Workload Control in DRC high-variety shops through a broad set of simulation experiments. By considering different labor assignment rules (When and Where rules), dispatching rules, shop types (undirected and directed routings), staffing levels, and two different approaches to handling the resulting overload - a decrease in the arrival rate of jobs and an increase in the service rate (i.e. the operating speed or efficiency) - we seek to provide guidance to managers on how best to handle fluctuations in labor availability. For example, while prior literature has highlighted the need to adjust the arrival and/or service rate in response to changes in the staffing level (e.g. Nelson, 1967; Hogg et al., 1975; Yang, 2007), the operational impact of the two approaches has, to the best of our knowledge, never been compared.

The remainder of this paper is structured as follows. In Section 2, we review relevant literature, including on labor assignment rules and methods for controlling the workload, and we outline the research questions that motivate our study. The specific Workload Control approach and the simulation model used to evaluate performance are then described in Section 3. The results are presented, discussed, and analyzed in Section 4 before conclusions are presented in Section 5.

\section{Literature Review}

This section provides an overview of the literature on DRC shops from an operational perspective; for a more detailed review, the reader is referred to Hottenstein \& Bowman (1998), Treleven (1989), and Xu et al. (2011). From an operational perspective, three elements need to be aligned 
in a DRC shop: (i) machine capacity; (ii) worker capacity; and, (iii) the workload (or demand). Most research has assumed that the machine capacity is fixed and has therefore focused on the remaining two elements: worker capacity and associated labor assignment rules driven by questions concerning when, where, and who to (re)assign to a station; and, the workload, which is controlled by dispatching and order release rules. These two streams of literature will be reviewed in Section 2.1 and Section 2.2, respectively. A discussion of the literature is then provided in Section 2.3.

Note that there is another stream of research that seeks to combine control of the workload with the labor assignment decision, i.e. the literature on advanced scheduling techniques (e.g. El Maraghy et al., 2000; Araz \& Salum, 2010; Jaber \& Neumann, 2010; Lei \& Guo, 2014; Lei \& Guo, 2015; Li et al., 2016; Zheng \& Wang, 2016; Zhang et al., 2017). But this stream of research presupposes that demand and capacity availability are known in advance and therefore deterministic. In contrast, we consider an environment where processing times, routings, and the inter-arrival times of orders follow a stochastic process. Advanced scheduling techniques, which presuppose a deterministic context, are therefore not considered further in our study.

\subsection{Labor Assignment Rules}

Most of the literature on DRC shops focuses on staffing decisions, labor efficiency, or labor assignment. For example, Felan et al. (1993) assessed the impact of labor flexibility in terms of the number of machines a worker can operate and compared the impact of a flexible labor force with a general increase in labor capacity (or the staffing level). They highlighted that the two decisions, labor flexibility and staffing level, should play complementary roles. Later, Felan \& Fry (2001) assessed different levels of flexibility across workers, i.e. where some workers are able to work on all machines and some workers are only able to work on one machine. They showed that having a small number of highly flexible workers may be a better option than having all workers with an average level of flexibility. These findings however are in the context of perfectly interchangeable workers, i.e. efficiency at a machine was considered to be either $100 \%$ or zero. The first study that questioned the assumption of perfectly interchangeable workers was by Bobrowski \& Park (1993) who introduced a labor efficiency matrix that determined the efficiency of a certain worker at a certain machine. Bobrowski \& Park (1993) also investigated five "when" and seven "where" rules, demonstrating that a simple "where" rule that moves a worker to the station where the worker is most efficient dominates all other Where and When rules. In addition 
to deciding when a worker should be transferred and where the worker should be transferred to, managers also have to decide who (i.e. which worker) to transfer; but this need to decide who is assigned to a station was only later emphasized by Bokhorst et al. (2004).

In general, there are only two types of When Rule used in the literature: a 'centralized' rule that may transfer a worker each time a job is completed; and, a 'decentralized' rule that only transfers a worker after all jobs at the current station (both in-process and queuing) have been completed. In contrast, there is a broad set of different Where rules available, but the literature has typically argued that the Where Rule has less of an impact on DRC shop performance than the When Rule (Xu et al. 2011). Finally, Who rules appear to be dominated by efficiency considerations (Bobrowski \& Park, 1993). In this study, we will therefore only consider When and Where rules since we assume all workers are fully trained and interchangeable, thus no efficiency differences exist. This simplification is justified by the need to keep our study to a manageable number of experimental variables. The simplification also leads us to omit another important stream of literature on labor assignment, specifically in the context of cross-trained workforces that may possess different skill levels - that on learning/forgetting (e.g. Malhotra et al., 1993; Fry et al., 1995; Kher et al., 1999; Kher, 2000b; Kannan \& Jensen, 2004; Zamiska et al., 2007; Yue et al., 2008).

\subsection{Control of the Workload - Order Release}

While there is a broad literature on DRC shops, literature specifically on the impact of order release in DRC shops is scarce. To the best of our knowledge, there are only three relevant studies: Bobrowski \& Park (1989), Park \& Bobrowski (1989), and Fredendall et al. (1996). All three use a similar shop model with the same staffing level: 50\%. Bobrowski \& Park (1989) assessed the impact of four different order release rules (Immediate Release, Backward Infinite Loading, Forward Finite Loading, and Maximum Shop Load) and two dispatching rules (Modified Operation Due Date and Critical Ratio) on a DRC job shop. The authors showed that Backward Infinite Loading and Forward Finite Loading can improve performance compared to Immediate Release, i.e. no order release control. These two release methods were also considered by Park \& Bobrowski (1989) along with three levels of labor flexibility (modeled by labor efficiency matrices) and two labor assignment rules. The authors' results revealed no statistically significant performance differences between the release methods. Finally, Fredendall et al. (1996) highlighted the positive impact of a triggering mechanism that limits the workload compared to release 
methods based on infinite loading, as applied in Bobrowski \& Park (1989) and Park \& Bobrowski (1989). However, this triggering mechanism does not lead to load balancing, one of the major strengths of workload control order release (Thürer et al., 2014b). No study to date has assessed the impact of the more effective load limiting workload control release methods that have been recently presented in the literature in the context of a DRC shop.

\subsection{Discussion of the Literature}

From the above review it becomes evident that although a broad literature exists on DRC shops, literature on the impact of order release in DRC shops is scarce. While this literature (Bobrowski \& Park 1989; Park \& Bobrowski, 1989; Fredendall et al., 1996) generally agrees on the potential of order release to improve performance in DRC shops, all use a similar shop model and the same staffing level. Hence, it does not assess how fluctuations in the staffing level affect order release performance. Moreover, the few prior studies all precede recent advances on order release control that have led to more effective load-limiting order release methods, specifically in the context of the Workload Control concept (e.g. Thürer et al., 2012). Yet the Workload Control literature typically considers only a single capacity constraint. In fact, further research that supports the implementation of Workload Control in DRC shops in practice was outlined as an important future study direction by Stevenson et al. (2011). In response, this paper seeks to combine both streams of literature - on Workload Control and DRC shops - by first asking:

RQ1: What is the impact of Workload Control order release on the performance of a DRC shop under different staffing levels?

An important finding from previous literature on order release in DRC shops is that order release performance can be improved by incorporating labor information into the release decision (Fredendall et al., 1996). This finding however was in the context of backward infinite loading and simple triggering mechanisms. These mechanisms do not consider load balancing and they were recently shown to be outperformed by Workload Control release mechanisms. Therefore, our second research question asks:

RQ2: Can the inclusion of information on labor availability further improve the performance of Workload Control order release in a DRC shop? 
Controlled simulation experiments will be used next to answer our two research questions. By considering different labor assignment rules (When and Where rules), dispatching rules, shop types (undirected and directed routings), staffing levels, and two different approaches to handling an overload - a lower inter-arrival rate of jobs and an increase in the service rate - we seek to provide guidance to managers on how best to make control decisions in the context of multiple resource constraints. The following section outlines the simulation model used in the experiments and the Workload Control order release methods incorporated in our study.

\section{Simulation}

A stylized standard model will be used in this study to avoid interactions that may otherwise interfere with our understanding of the main experimental factors. While any individual DRC shop in practice will differ in many aspects from our stylized environment, the model used in this study captures the job and shop characteristics of high variety make-to-order shops, i.e. high routing variability, high processing time variability, and high arrival time variability. The shop and job characteristics modeled in the simulations are first summarized in Section 3.1. How we model the order release methods considered in this study is then outlined in Section 3.2 before the different labor assignment rules are discussed in Section 3.3. The priority dispatching rules applied for controlling the progress of orders on the shop floor are then described in Section 3.4. Finally, the experimental design is outlined and the measures used to evaluate performance are presented in Section 3.5 .

\subsection{Overview of Modeled Shop and Job Characteristics}

A simulation model of a randomly routed job shop (or pure job shop) and of a general flow shop, where the routing is directed, has been implemented in Python ${ }^{\odot}$ using the $\mathrm{SimPy}^{\odot}$ module. We have kept our DRC shop relatively small since this allows causal factors to be identified more easily. Small systems provide a better insight into the role of operating variables and, in practice, large systems can often be decomposed into several smaller systems (Bokhorst et al. 2004). At the same time, we decided on a size that allows for comparison with previous studies on Workload Control (e.g. Melnyk \& Ragatz, 1989; Land \& Gaalman, 1998; Thürer et al., 2012). Thus, the shop contains six stations, where each is a single resource with constant capacity; and, as in previous DRC research, we consider machine capacity to be constant and focus on different levels of labor capacity. We experimented with three different staffing levels: 5 workers, 4 workers, and 3 
workers (50\% staffing). As in previous studies, a 50\% staffing is the lowest level (e.g. Felan et al., 1993). We assume that workers are fully trained and fully interchangeable. This simplification is justified by the need to keep the number of experimental factors manageable.

The routing of a job is determined by first drawing the routing length (i.e. the number of stations in the routing) from a discrete uniform distribution that varies from one to six operations; and, second, by selecting the stations by randomly drawing the required number from the set of stations without replacement. All stations have an equal probability of being visited and a particular station is required at most once in the routing of a job. The resulting routing vector is sorted for the general flow shop. Operation processing times follow a truncated 2-Erlang distribution with a maximum of 4 time units and a mean of 1 time unit after truncation. Set-up times are considered sequence independent and part of the operation processing time.

The inter-arrival time of jobs follows an exponential distribution. Workers are, on average, occupied $95 \%$ of the time. While this is higher than the $87.5 \%$ or $90 \%$ utilization typically applied in this kind of shop model under full staffing (e.g. Melnyk \& Ragatz, 1989; Land \& Gaalman, 1998; Thürer et al., 2012), it is justified by the potential to shift labor from idle stations to stations with work. Two approaches are used to ensure equal worker utilization for the different staffing levels: (i) the inter-arrival rate is adjusted (as in Yang, 2007); and, (ii) the service rate is adjusted (as in Nelson, 1967; Hogg et al., 1975), which is modeled by multiplying the processing time by a factor given by the number of workers divided by 6 (i.e. the number of stations). Adjusting the inter-arrival rate at a higher level of the planning system (as in Fredendall \& Melnyk, 1995) can be achieved in practice by delaying orders (see, e.g. Melnyk et al. (1991) and Park \& Salegna (1995)). This takes advantage of the lead time allowance. Meanwhile, the adjustment to the service rate takes advantage of the capacity buffer inherent in each worker; see, for example, Schultz et al. (1998) who demonstrated the phenomenon of speeding up behavior through a laboratory experiment.

Finally, due dates are set exogenously by adding a random allowance factor, uniformly distributed between 28 and 36 time units, to the job entry time. The minimum due date allowance of 28 time units corresponds to the requirements for the longest routing length of 6 operations (24 time units) plus an allowance for queuing and the pool waiting time. 


\subsection{Order Release and Refinements}

There are many order release methods in the Workload Control literature; for examples, see the reviews by Wisner (1995), Land \& Gaalman (1996), Bergamaschi et al. (1997), and Fredendall et al. (2010). In this paper, the LUMSCOR (Lancaster $\underline{\text { University }}$ Management $\underline{\mathrm{S}}$ chool Corrected Order Release) method is used because it was recently shown to be the best order release solution for Workload Control (Thürer et al., 2012). LUMSCOR uses a periodic release procedure executed at fixed intervals to control and balance the shop floor workload. This procedure keeps the workload $W_{s}$ released to a station $s$ within a pre-established workload norm, as follows:

(1) All jobs in the set of jobs $J$ in the pre-shop pool are sorted according to their planned release date.

(2) The job $j \in J$ with the earliest planned release date is considered for release first.

(3) Take $R_{j}$ to be the ordered set of operations in the routing of job $j$. If job $j$ 's processing time $p_{i j}$ at the $i^{\text {th }}$ operation in its routing - corrected for station position $i$-together with the workload $W_{s}$ released to station $s$ (corresponding to operation $i$ ) and yet to be completed fits within the workload norm $N_{s}$ at this station, that is $\frac{p_{i j}}{i}+W_{s} \leq N_{s} \forall i \in R_{j}$, then the job is selected for release. That means it is removed from $J$, and its load contribution is included, i.e. $W_{s}:=W_{s}+$ $\frac{p_{i j}}{i} \forall i \in R_{j}$. Otherwise, the job remains in the pool and its processing time does not contribute to the station load.

(4) If the set of jobs $J$ in the pool contains any jobs that have not yet been considered for release then return to Step 2 and consider the job with the next highest priority. Otherwise, the release procedure is complete and the selected jobs are released to the shop floor.

A released job contributes to $W_{s}$ until its operation at this station has been completed. Therefore, the load contribution to a station in LUMSCOR is calculated by dividing the processing time of the operation at a station by the station's position in the job's routing. This "corrected" aggregate load method (Oosterman et al., 2000) recognizes that a job's contribution to a station's direct load is limited to only the proportion of the total time the job spends on the shop floor that it is actually at the station.

In addition to the above periodic release mechanism, LUMSCOR incorporates a continuous workload trigger. If the load of any station falls to zero, the first job in the pool sequence with that station as the first in its routing is released irrespective of whether this would exceed the workload 
norms of any station. When the continuous workload trigger releases a job, its workload contribution to a station is calculated using the same corrected aggregate load approach as used for the periodic release time element of LUMSCOR.

\subsubsection{Proposed Order Release Refinements}

Two release methods will be considered in this study: the original LUMSCOR approach, as described above, and a refined version of LUMSCOR that takes labor availability into account. As in Fredendall et al. (1996), jobs are released on a continuous basis under the refined version of LUMSCOR when a station is idle and a worker for that station is available, i.e. processing can start immediately. There is no refinement to the periodic element since future labor availability remains unknown.

\subsubsection{Implementation of Order Release in the Simulation}

As in previous simulation studies on Workload Control and DRC shops, it is assumed that all jobs are accepted, materials are available, and all necessary information, e.g. regarding shop floor routings and processing times, is known. Jobs flow into a pre-shop pool to await release according to the original LUMSCOR and the refined LUMSCOR, which considers labor availability as part of its continuous release element. The main experimental factor for the release decision that is considered in our experiments is the workload norm. Seven workload norm levels are considered: from 4 (the maximum possible processing time) to 10 time units. The time interval between releases for the periodic element is set to 4 time units (based on the maximum possible processing time). Only one level is considered since a larger release interval led to worse performance in previous studies (Perona \& Portioli, 1998; Land, 2006). The constant allowance for the operation throughput time used for calculating planned release dates is set to 3 time units based on preliminary simulation experiments. Finally, as a baseline measure, experiments without controlled order release have also been executed, i.e. where jobs are released onto the shop floor immediately upon arrival. This is referred to as Immediate Release (IMM).

\subsection{Labor Assignment Rules}

Two When rules are considered: (i) Centralized, where a worker is eligible for transfer after each job completion; and, (ii) Decentralized, where a worker is eligible for transfer once the queue of the current station is empty. We also consider two Where rules: (i) the Maximum number of jobs in queue (MaxJob) rule, where a worker is transferred to the station with the longest queue 
measured in terms of the number of jobs (which may be the current station or a station without labor); and, (ii) the Earliest Due Date (EDD) rule, where a worker is transferred to the station with the queue that contains the job with the most urgent due date (which may be the current station or a station without labor). Note that, for MaxJob, a tie may occur, i.e. several stations may have the same (maximum) number of jobs. This tie is resolved by using the EDD rule.

The MaxJob rule was included as it is a standard rule that has been widely applied in previous research. The EDD rule was included due its good performance in Jensen (2000). Other rules, such as the shortest processing time rule, were not considered since they did not lead to performance improvements in previous studies (see, e.g. Park 1991). Since we consider workers to be fully interchangeable, no Who Rule is applied. Finally, if all stations without labor are empty, the worker goes to the central foreman to await work.

\subsection{Shop Floor Dispatching Rules}

The job that should be selected for processing next from the queue in front of a particular station is determined by a shop floor dispatching rule. In this study, two rules are applied: (i) the Earliest Due Date (EDD) rule, which prioritizes the job with the most urgent due date; and, (ii) the Modified Opperation Due Date (MODD) rule (see, e.g. Baker \& Kanet, 1983). The MODD rule

prioritizes jobs according to the lowest priority number, which is given by the maximum of the operation due date $\delta_{i j}$ and earliest finish time. In other words, $\max \left(\delta_{i j}, t+p_{i j}\right)$ for an operation with processing time $p_{i j}$, where $t$ refers to the time when the dispatching decision is taken. The MODD rule shifts between a focus on ODDs to complete jobs on time and a focus on speeding up jobs through a focus on shortest processing times - during periods of high load, i.e. when multiple jobs exceed their ODD (Land et al., 2015).

The calculation of the operation due date $\delta_{i j}$ for the $i^{\text {th }}$ operation of a job $j$ follows Equation (1) below. The operation due date for the last operation in the routing of a job is equal to the due date $\delta_{j}$, while the operation due date of each preceding operation is determined by successively subtracting an allowance $c$ from the operation due date of the next operation. This allowance is set to 3 time units based on the operation throughput times realized in preliminary simulation experiments.

$\delta_{i j}=\delta_{j}-\left(n_{j}-i\right) \cdot c \quad i: 1 \ldots n_{j}$

$n_{j}$ - number of operations in the routing of job $j$ 


\subsection{Experimental Design and Performance Measures}

The experimental factors are summarized in Table 1. A full factorial design with $(2 \times 2 \times 2 \times 2 \times 8 \times 2 \times 2 \times 3) 1,536$ scenarios was used, and each scenario was replicated 100 times. Results were collected over 10,000 time units following a warm-up period of 3,000 time units. These parameters allowed us to obtain stable results while keeping the simulation run time to a reasonable level.

\section{[Take in Table 1]}

Three main performance measures are used to assess both workload balancing and delivery performance: (i) the lead time (i.e. the time when a job is completed minus the time when it arrived at the company); (ii) the percentage of tardy jobs; and, (iii) the mean tardiness - that is $T_{j}=\max \left(0, L_{j}\right)$, with $L_{j}$ being the lateness of job $j$ (i.e. the actual delivery date minus the due date of job $j$ ). In addition to these three main performance measures, we also measure the average shop floor throughput time as an instrumental performance variable. While the lead time includes the time that a job waits in the pool prior to release, the shop floor throughput time only measures the time after release to the shop floor.

\section{Results}

Statistical analysis of our results was first conducted using an ANOVA (Analysis of Variance). ANOVA is here based on a block design, which is typically used to account for known sources of variation in an experiment. In our ANOVA, we treat the workload limit, shop type, adjustment type (to ensure 95\% worker occupation), and staffing level as blocking factors. This allows the main effects of these factors and the main and interaction effects of our four control related factors - the release method, our two types of labor assignment rules (i.e. the When and Where rules), and the dispatching rule - to be captured. The results are presented in Table 2 and Table 3 for lead time performance and tardiness related performance, respectively. All main effects, except for the Where Rule in terms of the percentage tardy, and the majority of the two-way interactions were shown to be statistically significant at $\alpha=0.05$. The two-way interaction between release method and Where Rule was not shown to be statistically significant for any of the performance measures 
considered. There are also some significant three-way interactions while all four-way interactions were found not to be statistically significant.

\section{[Take in Table $2 \&$ Table 3]}

To further assess these performance differences, detailed performance results will be presented next in Section 4.1. Here we focus on the release method, When Rule, Where Rule, and dispatching rule for one setting of the shop type, adjustment type, and staffing level. The impact of these three blocking factors is then examined in Section 4.2 to assess the robustness of our results. Finally, a discussion of the results is presented in Section 4.3.

\subsection{Performance Assessment}

To aid their interpretation, the results are presented in the form of performance curves. The lefthand starting point of the curves represents the lowest workload norm (4 time units). The workload norm increases step-wise by moving from left to right in each graph, with each data point representing one norm level (from 4 to 10 time units). Loosening the norm increases the level of work-in-process and, as a result, lengthens the shop floor throughput time. In addition, the results for immediate release are given by a single data point. These results are located to the right in each graph since they lead to the highest level of work-in-process. Figures 1a, 1b, 1c, and 1d show the lead time, percentage tardy, and mean tardiness over the shop floor throughput time results for the different combinations of When and Where rules. Figure 1a and Figure 1b present the results for the original and refined LUMSCOR release rules under EDD dispatching, respectively. Figure 1c and Figure 1d represent the same results under MODD dispatching. Only results for the pure job shop, an adjustment to the inter-arrival rate, and a staffing level of 4 workers are shown here, with the impact of changing these three factors assessed in the next section (Section 4.2). In the remainder of this section we discuss the results in terms of labor assignment rules, order release, and dispatching rule in Section 4.1.1 to 4.1.3, respectively.

\section{[Take in Figure 1]}

\subsubsection{Labor Assignment Rules (When and Where Rules)}

The performance of the different combinations of When and Where rules in isolation can be observed from the results for immediate release (i.e. the single right-hand data points in each graph). Results show a superior performance of the centralized When Rule. If a decentralized 
When Rule is applied, a worker is only eligible for transfer once the queue of the current station is empty. This favors jobs with short routings since low priority jobs (according to the Where Rule) may also be processed. In contrast, if the centralized When Rule is applied, a worker is eligible for transfer after each job completion. This favors jobs with long routings compared to a decentralized When Rule, as can be observed from Table 4, which gives the immediate release results from Figure 1 collected for each routing length. Favoring jobs with long routings leads to performance improvements overall since jobs with long routings are at a higher risk of becoming tardy than jobs with short routings.

\section{[Take in Table 4]}

Meanwhile, specifically for a decentralized When Rule, the more jobs there are in a queue the more likely it is that the most urgent job is also present in this queue. This explains why the performance of the EDD rule is similar to that of the MaxJob rule. However, under MODD dispatching (Figure 1c and Figure 1d), performance differences due to the Where Rule increases. If there is a long queue, many jobs are urgent. While EDD dispatching selects the most urgent job, MODD dispatching selects the job with the lowest processing time among urgent jobs.

\subsubsection{Impact of Order Release}

The impact of order release can be observed by comparing the single right-hand data points in each graph with the corresponding performance curves. Results suggest that significant performance improvements can be obtained through order release control for all performance measures except the percentage tardy and the scenario where a centralized When Rule, the MaxJob Where Rule, and MODD dispatching are applied (Figure 1c and Figure 1d). This is the experimental setting in which the strong focus on shortest processing times discussed in Section 4.1.1 above occurred. Meanwhile, tightening the norm (i.e. moving from right to left along each curve) reduces performance differences across When and Where rules, as somewhat expected, since queues become smaller and consequently selection possibilities are reduced. This reduction in queues is also likely to lead to more labor transfers if a decentralized When Rule is applied.

The impact of the refinement to the release method, i.e. only releasing a job through the continuous element of LUMSCOR if there is labor available, can be observed by comparing the results in Figure 1a with those in Figure 1b and by comparing Figure 1c with Figure 1d. Compared 
to the original release method, no significant performance improvements can be observed. This means the original LUMSCOR method can be retained in a DRC shop.

\subsubsection{Priority Dispatching}

The dispatching rule has relatively little direct impact on performance since labor assignment rules and order release restrict the selection possibilities. However, dispatching may lead to significant interaction effects, influencing the performance of the Where Rule (see Section 4.1.1 above). Dispatching also has a significant effect on the number of labor transfers incurred by the different combinations of When and Where rules. This can be observed from Table 5, which gives the number of labor transfers per 100 time units for the immediate release results from Figure 1. Table 5 provides the results for labor transfer caused by the Where Rule, labor transfer caused by a station being idle, and we indicate the total number of labor transfers (i.e. the sum of both), and the number of transfers to the central foreman (i.e. no transfer to another station).

\section{[Take in Table 5]}

From the table, a noteworthy reduction in labor transfers for the centralized When Rule and EDD Where Rule can be observed if MODD dispatching is applied instead of EDD dispatching. Under EDD dispatching, the most urgent job is selected for processing. This means that, after processing, the most urgent job is no longer in this queue. In contrast, for MODD dispatching, the job with the shortest processing time in the set of urgent jobs is chosen. Therefore, the most urgent job may still be in this queue. Finally, and as expected, the decentralized When Rule leads to fewer labor transfers than the centralized When Rule.

\subsection{Robustness Analysis}

In this section we discuss the results in terms of our three blocking factors - shop type, adjustment type, and staffing level - in Section 4.2.1 to 4.2.3, respectively.

\subsubsection{Impact of the Shop Type (Undirected vs. Directed Routing)}

Figure $2 \mathrm{a}$ to Figure $2 \mathrm{~d}$ present the results for the same setting as in Figure 1 but for the general flow shop where the routing is directed.

[Take in Figure 2] 
In terms of labor assignment rules, it can be observed that the relative performance of the different combinations of When and Where rules is not affected by the shop type. However, the performance difference between the EDD Where Rule and MaxJob Where Rule increases significantly for a centralized When Rule if EDD dispatching is applied on the shop floor (Figure $2 \mathrm{a}$ and $2 \mathrm{~b}$ ). As we shift from an undirected to a directed routing, the likelihood of the Where Rule shifting to a station differs across stations. In a general flow shop, the last station (Station 6) is more likely to have the most urgent job in the queue than the first station. Meanwhile, although the last station also has higher variability in terms of the size of the queue, the likelihood that the last station is the one with the longest queue is less than the likelihood that the last station is the one with the most urgent job. As a result, the correlation between the station with the longest queue and the station with the most urgent job in the queue is weaker in the general flow shop, and two different patterns of labor transfer occur. For MaxJob, labor transfers are still relatively equally distributed since all stations are still more or less equally likely to have the longest queue; but for EDD, a distinct pattern occurs - labor stays longer at the last station and shifts more often to/from upstream stations. This can be observed from Table 6, which gives the number of labor transfers per 100 time units for the concerned scenario for each station. It is argued that the distinctive pattern created by the EDD When Rule explains the performance improvement observed.

\section{[Take in Table 6]}

In terms of order release control, the results in Figure 2 confirm the positive performance effect of order release and that tightening the norm (i.e. moving from right to left on each curve) reduces the performance differences between labor assignment rules. Meanwhile, no performance improvement can again be observed from using the refined release method. Finally, the interaction effects created by dispatching in the pure job shop are also maintained in the general flow shop.

\subsubsection{Impact of the Adjustment Type}

Our results are also robust to the different approaches to maintaining average labor occupation at a 95\% level: adjusting the inter-arrival rate and adjusting the service rate. This can be observed from Figure 3, which gives the results for the same scenarios as in Figure 1 (where we adjusted the inter-arrival rate) but with an adjusted service rate.

[Take in Figure 3] 
Importantly, while the relative performance of the order release control methods and the labor assignment rules appears to be unaffected, a general performance improvement can be observed for adjustments in the service rate. A first explanation of this effect is the lower processing time. For example, for a staffing level of three, the average processing time reduces from 3.5 time units to 1.75 time units. However, this decrease is relatively small compared to the actual reduction in the lead time that can be observed. Hence, some other explanation is needed. In response, we recorded the workload contribution over time. While the average amount of workload in the system is the same for a given staffing level (as the labor utilization is the same), adjusting the service rate leads to a smoother workload over time, as can be seen from Figure 4 where a snapshot of the workload over time is provided. This in turn leads to improved performance. Another important observation that can be made by comparing Figure $4 \mathrm{a}$, which gives the workload distribution for a centralized When Rule, and Figure $4 b$, which gives the distribution for a decentralized When Rule, is that the latter leads to a smoother workload distribution over time.

\section{[Take in Figure 4]}

\subsubsection{Impact of the Staffing Level}

In general, performance improves compared to full staffing since labor can be shifted from idle stations to stations with work. This allowed for higher labor utilization (but lower station utilization) in our study when compared to studies that use a similar shop model but without a labor constraint. Meanwhile, the positive performance effect of adjusting the service rate instead of the inter-arrival rate can also be observed from Figure 5, which gives the performance results for the two different adjustment types and different staffing levels. Only results for the original LUMSCOR release method and EDD dispatching are given since performance effects are qualitatively similar. In fact, while lower staffing levels lead to a worsening of performance when the inter-arrival rate is adjusted (seen by comparing Figure 5a with Figure 5b), lower staffing levels lead to better performance if a reduction in staffing can be compensated for by an increase in service rate by the remaining labor (seen by comparing Figure $5 \mathrm{c}$ with Figure 5d). This comes somewhat as a surprise since the labor occupation for both the inter-arrival rate adjustment and service rate adjustment is deliberately the same - 95\%. It is partly explained by the actual reduction in processing time and, most importantly, the impact of processing time adjustments on the distribution of the incoming 
workload overtime. Both adjustments impact the distribution of the work input, and the difference in the distribution explains the majority of the performance differences.

[Take in Figure 5]

\subsection{Discussion of Results}

In general, it is argued in the literature that the Where Rule has less of a performance impact than the When Rule (Xu et al., 2011). Our results support this argument in the context of a pure job shop (i.e. undirected routing). More specifically, if the parameters that drive the Where Rule are highly correlated, such as the maximum number of jobs in a queue (MaxJob) and the most urgent job in the queue (EDD) in the context of our study, then performance differences between Where rules become negligible. However, our results question $\mathrm{Xu}$ et al.'s (2011) argument in settings where this correlation is weaker, as is the case in the general flow shop (i.e. when routings are directed).

In terms of order release control, Fredendall et al. (1996) highlighted the potential of including information on labor availability in the release decision for improving performance. This finding could not however be confirmed in the context of more effective order release methods that have emerged since Fredendall et al. (1996). Meanwhile, it was argued in the literature that more sophisticated dispatching rules lose their advantage when labor flexibility increases (Park, 1991). Our results support this argument, but they also highlight that the choice of dispatching rule leads to important interaction effects with the Where Rule. While order release, the When Rule, and the Where Rule limit the set of eligible jobs to choose between, it is still the dispatching rule that decides which job to process.

Finally, our results confirm Fredendall \& Melnyk's (1995) findings on the importance of the input distribution. Fredendall \& Melnyk (1995) showed that any reduction in variance through higher planning levels has the potential to dominate performance improvements achievable at order release, dispatching, and via a worker assignment rule. Our results complement those of Fredendall \& Melnyk (1995) as they focused on higher planning levels while we have highlighted that the input distribution is also influenced by lower level processing time adjustments, i.e. adjustments to the service rate. If labor is absent, the input of work to the shop needs to be reduced or capacity should be adjusted to avoid an overload (i.e. a worker occupation level in excess of 100\%). Capacity adjustments can be realized, for example, by working faster (i.e. reduced processing times) or through overtime by the remaining worker(s). Our study highlights that 
capacity adjustments are a better choice than adjusting the input distribution since this leads to workload smoothing.

\section{Conclusions}

A major aim of production planning and control concepts such as Workload Control is to align demand (or workload) and capacity. Most research on Workload Control (and other concepts) has assumed that capacity is a single variable, i.e. constrained by a single resource, namely machine capacity. In practice, most manufacturing systems are not only constrained by machine capacity but also by labor capacity. This type of highly complex shop is known in the literature as a Dual Resource Constrained (DRC) shop. Although a broad literature on DRC shops exists, literature specifically on order release in DRC shops is scarce. In response, our first research question asked: What is the impact of Workload Control order release on the performance of a DRC shop under different staffing levels? Using simulation we have demonstrated that order release has the potential to significantly improve DRC shop performance and that results are robust to changes in the staffing level. However, in response to our second research question - Can the inclusion of information on labor availability further improve the performance of Workload Control order release in a DRC shop? - our results have demonstrated that refining the order release method to incorporate labor information in the release decision does not provide any positive performance effects. This means managers can implement the original Workload Control release method (i.e. LUMSCOR) if labor is fully interchangeable. Further, by considering different labor assignment rules (When and Where rules), dispatching rules, shop types (undirected and directed routings), staffing levels, and two different approaches for handling an overload - a lower inter-arrival rate of jobs and an increase in service rate - we sought to not only contribute to the literature (as discussed in Section 4.3 above) but also to provide guidance to managers on how best to handle the absence of labor and make release decisions in the context of multiple resource constraints. This will be briefly discussed next before the paper closes with the limitations of our study and future research directions.

\subsection{Managerial Implications}

Our study was motivated by an important issue encountered when implementing Workload Control in practice: how to handle fluctuations in the supply of human resources caused, for example, by attrition, high labor turnover, or absenteeism. Our results suggest that the original 
Workload Control system can be implemented in DRC shops with fully interchangeable labor, i.e. LUMSCOR can be used whether there is a single or a dual constraint as refining the method to also incorporate labor information does not lead to any further improvements in release performance. LUMSCOR has the potential to improve performance regardless of the staffing level. In terms of transfer policy, a centralized When and urgency-based Where Rule should be applied to assign labor to stations. However, if transfer costs are high then a decentralized When Rule may be a better solution since it leads to significantly fewer transfers. Meanwhile, dispatching should be kept simple and, because of the interaction between dispatching and the Where Rule, the choice of dispatching rule should be aligned with the choice of Where Rule in terms of the priority value that determines the assignment and dispatching decision. Finally, the best way of handling labor absenteeism is by increasing the service rate enabling the remaining workers to work faster or undertake overtime.

\subsection{Limitations and Future Research}

A limitation of our study is that we assume workers are fully interchangeable, and we omit behavioral factors such as learning and forgetting. While this is justified by the need to keep our study focused, future research could take these factors into account. Meanwhile, our study has highlighted the potential of dynamic labor assignment rules that create a specific pattern that reflects, for example, routing characteristics. Future research is needed to design and test rules that support this aim. Araz \& Salum (2010) provided a first contribution in this direction by presenting a scheduling mechanism that dynamically reschedules labor assignments using alternative labor assignment rules. However, the authors did not consider the creation of a labor transfer pattern, as has been demonstrated here to significantly improve performance if the routing is directed. Finally, not having full staffing improves performance (when compared to having full staffing) since labor can be shifted from idle to loaded machines. This means that performance can be improved by increasing labor utilization at the expense of station utilization. This may provide the starting point for future research on staffing.

\section{References}

Araz, Ö.U., \& Salum, L., 2010, A multi-criteria adaptive control scheme based on neural networks and fuzzy inference for DRC manufacturing systems, International Journal of Production Research, 48, 1, 251-270. 
Baker, K.R., \& Kanet, J.J., 1983, Job shop scheduling with modified operation due-dates, Journal of Operations Management, 4, 1, 11-22.

Bechte, W., 1994, Load-oriented manufacturing control just-in-time production for job shops, Production Planning \& Control, 5, 3, 292 - 307.

Bergamaschi, D., Cigolini, R., Perona, M., \& Portioli, A., 1997, Order review and release strategies in a job shop environment: A review and a classification, International Journal of Production Research, 35, 2, 399-420.

Blumenfeld, D.E., \& Inman, R.R., 2009, Impact of Absenteeism on Assembly Line Quality and Throughput, Production \& Operations Management, 18, 3, 333-343.

Bobrowski, P.M., \& Park, P.S., 1993, An evaluation of labor assignment rules when workers are not perfectly interchangeable, Journal of Operations Management, 11, 257-268.

Bobrowski, P.M., \& Park, P.S., 1989, Work Release Strategies in a Dual Resource Constrained Job Shop, OMEGA, 17, 2, 177-188.

Bokhorst, J.A.C., \& Gaalman, G.J.C., 2009, Cross-training workers in Dual Resource Constrained systems with heterogeneous processing times, International Journal of Production Research, 47, 22, 6333-6356.

Bokhorst, J.C.A., Slomp, J., \& Gaalman G.J.C., 2004, On the who-rule in Dual Resource Constrained (DRC) manufacturing systems, International Journal of Production Research, 42, 23, 5049-5074.

Bukchin, Y., \& Cohen, Y., 2013, Minimising throughput loss in assembly lines due to absenteeism and turnover via work-sharing, International Journal of Production Research, 51, 20, 61406151 ,

ElMaraghy, H., Patel., V., \& Abdallah, I.B., 2000, Scheduling of Manufacturing Systems Under Dual-Resource Constraints Using Genetic Algorithms, Journal of Manufacturing Systems, 19, 3, 186-201.

Felan, J.T., \& Fry, T.D., 2001, Multi-level heterogeneous worker flexibility in a Dual Resource Constrained (DRC) job-shop, International Journal of Production Research, 39, 14, 3041-3059.

Felan, J.T., Fry, T.D., \& Philipoom, P.R., 1993, Labor flexibility and staffing levels in a dualresource constrained job shop, International Journal of Production Research, 31, 10, 24872506. 
Fredendall, L.D. \& Melnyk, S.A., 1995, Assessing the impact of reducing demand variance through improved planning on the performance of a dual resource constrained job shop, International Journal of Production Research, 33, 6, 1521-1534.

Fredendall, L.D., Melnyk, S.A., \& Ragatz, G., 1996, Information and scheduling in a dual resource constrained job shop, International Journal of Production Research, 34, 10, 2783-2802.

Fredendall, L.D., Ojha, D., \& Patterson, J.W., 2010, Concerning the theory of workload control, European Journal of Operational Research, 201, 1, 99-111.

Fry, T.D., Kher, H.V., \& Malhotra, M.K., 1995, Managing worker flexibility and attrition in dual resource constrained job shops, International Journal of Production Research, 33, 8, 2163-2179.

Hendry, L.C., Huang, Y., \& Stevenson, M., 2013, Workload control: Successful implementation taking a contingency-based view of production planning and control, International Journal of Operations \& Production Management, 33, 1, 69-103.

Hogg, G.L., Phillips, D.T., Maggard, M.J., \& Lesso, W.G., 1975, GERTS QR: A Model for MultiResource Constrained Queueing Systems Part II: An Analysis of Parallel-Channel, DualResource Constrained Queueing Systems with Homogeneous Resources, AIIE Transactions, 7, 2, 100-109,

Hottenstein, M.P., \& Bowman, S.A., 1998, Cross-training and Worker flexibility: A review of DRC System research, The Journal of High Technology Management Research, 9, 2, 157-174.

Jaber, M.Y., \& Neumann, W.P., 2010, Modelling worker fatigue and recovery in dual-resource constrained systems, Computers \& Industrial Engineering, 59, 75-84.

Jensen, J.B., 2000, The impact of resource flexibility and staffing decisions on cellular and departmental shop performance, European Journal of Operational Research, 127, 279-296.

Kannan, V.R., \& Jensen, J.B., 2004, Learning and labor assignment in a dual resource constrained cellular shop, International Journal of Production Research, 42, 7, 1455-1470.

Kher, H.V., 2000a, Examination of worker assignment and dispatching rules for managing vital customer priorities in dual resource constrained job shop environments, Computers and Operations Research, 27, 525-537.

Kher, H.V., 2000b, Examination of flexibility acquisition policies in dual resource constrained job shops with simultaneous worker learning and forgetting effects, Journal of the Operational Research Society, 51, 592-601. 
Kher, H.V., Malhotra, M.K., Philipoom, P.R., \& Fry, T.D., 1999, Modeling simultaneous worker learning and forgetting in dual resource constrained systems, European Journal of Operational Research, 115, 158-172.

Land, M.J., 2006, Parameters and sensitivity in workload control, International Journal of Production Economics, 104, 625-68.

Land, M.J., \& Gaalman, G.J.C., 1998, The performance of workload control concepts in job shops: Improving the release method, International Journal of Production Economics, 56- 57, 347364.

Land, M.J., \& Gaalman, G.J.C, 1996, Workload control concepts in job shops: A critical assessment, International Journal of Production Economics, 46-47, 535-538.

Land, M.J., Stevenson, M., Thürer, M., \& Gaalman, G.J.C., 2015, Job Shop Control: In Search of the Key to Delivery Improvements, International Journal of Production Economics, 168, 257266.

Lei, D., \& Guo, X., 2015, An effective neighbourhood search for scheduling in dual-resource constrained interval job shop with environmental objective, International Journal of Production Economics, 159, 296-303.

Lei, D., \& Guo, X., 2014, Variable neighbourhood search for dual-resource constrained flexible job shop scheduling, International Journal of Production Research, 52, 9, 2519-2529.

Li, J., Huang, Y., \& Niu, X., 2016, A branch population genetic algorithm for dual-resource constrained job shop scheduling problem, Computers \& Industrial Engineering, 102, 113-131.

Malhotra, M.K., \& Kher, H.V., 1994, An evaluation of worker assignment policies in dual resource-constrained job shops with heterogeneous resources and worker transfer delays, International Journal of Production Research, 32, 5, 1087-1103.

Malhotra, M.K., Fry, T.D., Kher, H.V., \& Donohue, J.M., 1993, The Impact of Learning and Labor Attrition on Worker Flexibility in Dual Resource Constrained Job Shops, Decision Sciences, $24,3,641-664$.

Melnyk, S.A., Ragatz, G.L., \& Fredendall, L.D., Load Smoothing by the Planning and Order Review/Release Systems: A Simulation Experiment, Journal of Operations Management, 10, 4, Melnyk, S.A., \& Ragatz, G.L., 1989, Order review/release: research issues and perspectives, International Journal of Production Research, 27, 7, 1081-1096. 
Nelson, R.T., 1967, Labor and Machine Limited Production Systems, Management Science, 13, 9, 648-671.

Nembhard, D.A., 2014, Cross training efficiency and flexibility with process change, International Journal of Operations \& Production Management, 34, 11, 1417-1439.

Oosterman, B., Land, M.J., \& Gaalman, G., 2000, The influence of shop characteristics on workload control, International Journal of Production Economics, 68, 1, 107-119.

Park., P.S., 1991, The examination of worker cross-training in a dual resource constrained job shop, European Journal of Operational Research, 51, 291-299.

Park, P.S., \& Salegna, G.J., 1995, Load smoothing with feedback in a bottleneck job shop, International Journal of Production Research, 33, 6, 1549-1568.

Park, P.S., \& Bobrowski, P.M., 1989, Job Release and Labor Flexibility in a Dual Resource Constrained Job Shop, Journal of Operations Management, 8, 3, 230-249.

Perona, M., and Portioli, A., 1998, The impact of parameters setting in load oriented manufacturing control, International Journal of Production Economics, 55, 133-142.

Salum, L., \& Araz, Ö.U., 2009, Using the when/Where Rules in dual resource constrained systems for a hybrid push-pull control, International Journal of Production Research, 47, 6, 1661-1677.

Sammarco, M., Fruggiero, F., Neumann, W.P., \& Lambiase, A., 2014, Agent-based modelling of movement rules in DRC systems for volume flexibility: human factors and technical performance, International Journal of Production Research, 52, 3, 633-650.

Schultz, K.L., Juran, D.C., Boudreau, J.W., McClain, J.O., \& Thomas, L.J., 1998, Modeling and Worker Motivation in JIT Production Systems, Management Science, 44, 12, 1595-1607.

Slomp, J., \& Molleman E., 2002, Cross-training policies and team performance, International Journal of Production Research, 40, 5, 1193-1219.

Stevenson, M., Huang, Y., Hendry, L.C., \& Soepenberg, E., 2011, The theory and practice of workload control: A research agenda and implementation strategy, International Journal of Production Economics, 131, 2, 689-700.

Stevenson, M., Hendry, L.C., \& Kingsman, B.G., 2005, A review of production planning and control: The applicability of key concepts to the make to order industry, International Journal of Production Research, 43, 5, 869-898. 
Thürer, M., Stevenson, M., Silva, C., Land, M.J., \& Fredendall, L.D., 2012, Workload control (WLC) and order release: A lean solution for make-to-order companies, Production \& Operations Management, 21, 5, 939-953.

Thürer, M., Stevenson, M., Silva, C., Land, M.J., Fredendall, L.D., \& Melnyk, S.A., 2014, Lean control for make-to-order companies: Integrating customer enquiry management and order release, Production \& Operations Management, 23, 3, 463-476.

Thürer, M., Qu, T., Stevenson, M., Maschek, T., and Godinho Filho, M., 2014b, Continuous Workload Control Order Release Revisited: An Assessment by Simulation, International Journal of Production Research, 52, 22, 6664-6680.

Treleven, M.D., 1989, A Review of the Dual Resource Constrained System Research, IIE Transactions, 21, 3, 279-287

Wiendahl, H.P., Gläßner, J., \& Petermann, D., 1992, Application of load-oriented manufacturing control in industry, Production Planning \& Control, 3, 2, 118-129.

Wisner, J. D., 1995, A review of the order release policy research, International Journal of Operations \& Production Management, 15, 6, 25-40.

Yang, K.K., 2007, A comparison of cross-training policies in different job shops, International Journal of Production Research, 45, 6, 1279-1295.

Yue, H., Slomp, J., Molleman, E., \& Van Der Zee, D.J., 2008, Worker flexibility in a parallel dual resource constrained job shop, International Journal of Production Research, 46, 2, 451-467.

Xu, J., Xu., X., \& Xie, S.Q., 2011, Recent developments in Dual Resource Constrained (DRC) system research, European Journal of Operational Research, 215, 309-318.

Zamiska, J.R., Jaber, M.Y., \& Kher, H.V., 2007, Worker deployment in dual resource constrained systems with a task-type factor, European Journal of Operational Research, 177, 1507-1519.

Zäpfel, G. \& Missbauer, H., 1993, New concepts for production planning and control, European Journal of Operational Research, 67, 297-320.

Zhang, J., Wang, W., \& Xu, X., 2017, A hybrid discrete particle swarm optimization for dualresource constrained job shop scheduling with resource flexibility, Journal of Intelligent Manufacturing, 28, 1961-1972.

Zheng, X.L., \& Wang, L., 2016, A knowledge-guided fruit fly optimization algorithm for dual resource constrained flexible job-shop scheduling problem, International Journal of Production Research, 54, 18, 5554-5566. 
Table 1: Experimental Settings

\begin{tabular}{r|l}
\hline Factors & Levels \\
Release Methods & Original and Refined LUMSCOR \\
Where Rules & Centralized and Decentralized \\
EDD (Earliest Due Date) and MaxJob (Maximum Number of Jobs) \\
Dispatching Rules & EDD and MODD (Modified Operation Due Date) \\
Norm Levels & IMM, 10, 9, 8, 7, 6, 5, 4 \\
Shop Types & $\begin{array}{l}\text { Pure Job Shop (random, undirected routing) and General Flow Shop } \\
\text { (random, directed routing) } \\
\text { Adjustment Types }\end{array}$ \\
Inter-arrival rate adjusted and service rate adjusted \\
Staffing Levels
\end{tabular}

Table 2: ANOVA Results (Lead Time Performance)

\begin{tabular}{|c|c|c|c|c|c|c|}
\hline & Source of Variance & $\begin{array}{r}\text { Sum of } \\
\text { Squares }\end{array}$ & $\begin{array}{l}\text { Degree of } \\
\text { Freedom }\end{array}$ & $\begin{array}{r}\text { Mean } \\
\text { Squares }\end{array}$ & F-Ratio & $\begin{array}{c}\text { p- } \\
\text { Value }\end{array}$ \\
\hline \multirow{20}{*}{ Lead Time } & Release Method (RM) & 36059.21 & 1 & 36059.21 & 2329.57 & 0.00 \\
\hline & When Rule & 23277.32 & 1 & 23277.32 & 1503.81 & 0.00 \\
\hline & Where Rule & 704.84 & 1 & 704.84 & 45.54 & 0.00 \\
\hline & Dispatching (Disp) & 6827.89 & 1 & 6827.89 & 441.11 & 0.00 \\
\hline & Norm & 16028.42 & 7 & 2289.77 & 147.93 & 0.00 \\
\hline & ShopType & 23211.94 & 1 & 23211.94 & 1499.59 & 0.00 \\
\hline & Adjustment & 1428000.90 & 1 & 1428000.90 & 92254.69 & 0.00 \\
\hline & Staffing & 224122.35 & 2 & 112061.17 & 7239.61 & 0.00 \\
\hline & RM x When & 495.07 & 1 & 495.07 & 31.98 & 0.00 \\
\hline & RM $\times$ Where & 2.80 & 1 & 2.80 & 0.18 & 0.67 \\
\hline & RM x Disp & 433.07 & 1 & 433.07 & 27.98 & 0.00 \\
\hline & When $x$ Where & 130.33 & 1 & 130.33 & 8.42 & 0.00 \\
\hline & When x Disp & 203.01 & 1 & 203.01 & 13.12 & 0.00 \\
\hline & Where $x$ Disp & 1.07 & 1 & 1.07 & 0.07 & 0.79 \\
\hline & RM $\times$ When $\times$ Where & 5.85 & 1 & 5.85 & 0.38 & 0.54 \\
\hline & RM x When x Disp & 113.80 & 1 & 113.80 & 7.35 & 0.01 \\
\hline & RM $\times$ Where $\times$ Disp & 2.01 & 1 & 2.01 & 0.13 & 0.72 \\
\hline & When $x$ Where $x$ Disp & 19.98 & 1 & 19.98 & 1.29 & 0.26 \\
\hline & RM $\times$ When $\times$ Where $\times$ Disp & 0.95 & 1 & 0.95 & 0.06 & 0.80 \\
\hline & Residual & 2377140.70 & 153573 & 15.48 & & \\
\hline
\end{tabular}


Table 3: ANOVA Results (Tardiness Performance)

\begin{tabular}{|c|c|c|c|c|c|c|}
\hline & Source of Variance & $\begin{array}{r}\text { Sum of } \\
\text { Squares }\end{array}$ & $\begin{array}{c}\text { Degree of } \\
\text { Freedom }\end{array}$ & $\begin{array}{r}\text { Mean } \\
\text { Squares }\end{array}$ & F-Ratio & $\begin{array}{c}\text { p- } \\
\text { value }\end{array}$ \\
\hline \multirow{20}{*}{$\begin{array}{l}\text { Percentage } \\
\text { Tardy }\end{array}$} & Release Method (RM) & 5.47 & 1 & 5.47 & 1360.15 & 0.00 \\
\hline & When Rule & 17.22 & 1 & 17.22 & 4284.22 & 0.00 \\
\hline & Where Rule & 0.01 & 1 & 0.01 & 3.22 & 0.07 \\
\hline & Dispatching (Disp) & 29.83 & 1 & 29.83 & 7423.05 & 0.00 \\
\hline & Norm & 4.65 & 7 & 0.66 & 165.26 & 0.00 \\
\hline & Shop Type & 11.71 & 1 & 11.71 & 2912.92 & 0.00 \\
\hline & Adjustment & 314.91 & 1 & 314.91 & 78368.38 & 0.00 \\
\hline & Staffing & 12.75 & 2 & 6.37 & 1586.15 & 0.00 \\
\hline & RM $\times$ When & 0.16 & 1 & 0.16 & 39.62 & 0.00 \\
\hline & RM $\times$ Where & 0.00 & 1 & 0.00 & 0.37 & 0.54 \\
\hline & RM x Disp & 0.14 & 1 & 0.14 & 35.95 & 0.00 \\
\hline & When $x$ Where & 0.27 & 1 & 0.27 & 68.15 & 0.00 \\
\hline & When x Disp & 0.14 & 1 & 0.14 & 34.62 & 0.00 \\
\hline & Where $x$ Disp & 0.44 & 1 & 0.44 & 108.56 & 0.00 \\
\hline & RM $\times$ When $\times$ Where & 0.00 & 1 & 0.00 & 0.09 & 0.76 \\
\hline & RM x When x Disp & 0.02 & 1 & 0.02 & 4.65 & 0.03 \\
\hline & RM $\times$ Where $\times$ Disp & 0.00 & 1 & 0.00 & 0.04 & 0.84 \\
\hline & When $x$ Where $x$ Disp & 0.21 & 1 & 0.21 & 51.45 & 0.00 \\
\hline & RM $\times$ When $x$ Where $x$ Disp & 0.00 & 1 & 0.00 & 0.04 & 0.84 \\
\hline & Residual & 617.11 & 153573 & 0.00 & & \\
\hline \multirow{20}{*}{$\begin{array}{c}\text { Mean } \\
\text { Tardiness }\end{array}$} & Release Method (RM) & 3712.52 & 1 & 3712.52 & 639.93 & 0.00 \\
\hline & When Rule & 12902.63 & 1 & 12902.63 & 2224.03 & 0.00 \\
\hline & Where Rule & 1335.30 & 1 & 1335.30 & 230.17 & 0.00 \\
\hline & Dispatching (Disp) & 30.81 & 1 & 30.81 & 5.31 & 0.02 \\
\hline & Norm & 16662.43 & 7 & 2380.35 & 410.30 & 0.00 \\
\hline & Shop Type & 7016.01 & 1 & 7016.01 & 1209.35 & 0.00 \\
\hline & Adjustment & 147488.24 & 1 & 147488.24 & 25422.64 & 0.00 \\
\hline & Staffing & 13753.27 & 2 & 6876.64 & 1185.33 & 0.00 \\
\hline & RM $\times$ When & 215.51 & 1 & 215.51 & 37.15 & 0.00 \\
\hline & RM $\times$ Where & 5.90 & 1 & 5.90 & 1.02 & 0.31 \\
\hline & RM x Disp & 127.30 & 1 & 127.30 & 21.94 & 0.00 \\
\hline & When $x$ Where & 410.60 & 1 & 410.60 & 70.77 & 0.00 \\
\hline & When x Disp & 225.77 & 1 & 225.77 & 38.92 & 0.00 \\
\hline & Where x Disp & 20.72 & 1 & 20.72 & 3.57 & 0.06 \\
\hline & RM $\times$ When $\times$ Where & 5.83 & 1 & 5.83 & 1.01 & 0.32 \\
\hline & RM x When x Disp & 80.93 & 1 & 80.93 & 13.95 & 0.00 \\
\hline & RM $\times$ Where $\times$ Disp & 1.38 & 1 & 1.38 & 0.24 & 0.63 \\
\hline & When $x$ Where $x$ Disp & 63.69 & 1 & 63.69 & 10.98 & 0.00 \\
\hline & RM $\times$ When $\times$ Where $\times$ Disp & 1.04 & 1 & 1.04 & 0.18 & 0.67 \\
\hline & Residual & 890946.59 & 153573 & 5.80 & & \\
\hline
\end{tabular}


Table 4: Performance Analysis - Centralized vs. Decentralized When Rule for Different Routing Lengths of Jobs under Immediate Release (Pure Job Shop, Inter-arrival Rate Adjusted, and a Staffing Level of 4 Workers)

\begin{tabular}{|c|c|c|c|c|c|c|c|c|c|}
\hline & \multirow{2}{*}{$\begin{array}{r}\text { Dispatching } \\
\text { Rule }\end{array}$} & \multirow{2}{*}{$\begin{array}{r}\text { Where } \\
\text { Rule }\end{array}$} & \multirow{2}{*}{$\begin{array}{r}\text { When } \\
\text { Rule }\end{array}$} & \multicolumn{6}{|c|}{ Routing Length (RL) of Jobs } \\
\hline & & & & $\mathrm{RL} 1$ & RL2 & RL3 & RL4 & RL5 & RL6 \\
\hline \multirow{8}{*}{$\begin{array}{l}\text { Lead } \\
\text { Time }\end{array}$} & \multirow{4}{*}{ EDD } & \multirow[t]{2}{*}{ EDD } & Centralized & 10.77 & 14.85 & 17.51 & 19.57 & 21.35 & 22.97 \\
\hline & & & Decentralized & 7.88 & 13.76 & 18.52 & 22.55 & 26.12 & 29.34 \\
\hline & & \multirow[t]{2}{*}{ MaxJob } & Centralized & 9.89 & 14.34 & 17.38 & 19.75 & 21.76 & 23.59 \\
\hline & & & Decentralized & 7.78 & 13.59 & 18.31 & 22.36 & 26.08 & 29.52 \\
\hline & \multirow{4}{*}{ MODD } & \multirow[t]{2}{*}{ EDD } & Centralized & 11.76 & 15.55 & 17.98 & 19.92 & 21.59 & 23.16 \\
\hline & & & Decentralized & 8.79 & 14.26 & 18.41 & 22.09 & 25.51 & 28.78 \\
\hline & & \multirow[t]{2}{*}{ MaxJob } & Centralized & 11.42 & 15.37 & 17.76 & 19.58 & 21.19 & 22.67 \\
\hline & & & Decentralized & 8.75 & 14.22 & 18.34 & 22.03 & 25.51 & 29.00 \\
\hline \multirow{8}{*}{$\begin{array}{r}\text { Percentage } \\
\text { Tardy }\end{array}$} & \multirow{4}{*}{ EDD } & \multirow[t]{2}{*}{ EDD } & Centralized & $7.13 \%$ & $10.23 \%$ & $12.73 \%$ & $15.02 \%$ & $17.32 \%$ & $19.66 \%$ \\
\hline & & & Decentralized & $2.77 \%$ & $8.19 \%$ & $14.57 \%$ & $20.80 \%$ & $26.47 \%$ & $31.73 \%$ \\
\hline & & \multirow{2}{*}{ MaxJob } & Centralized & $6.18 \%$ & $9.86 \%$ & $13.05 \%$ & $15.87 \%$ & $18.63 \%$ & $21.26 \%$ \\
\hline & & & Decentralized & $2.63 \%$ & $7.93 \%$ & $14.17 \%$ & $20.54 \%$ & $26.49 \%$ & $32.13 \%$ \\
\hline & \multirow{4}{*}{ MODD } & \multirow[t]{2}{*}{ EDD } & Centralized & $3.30 \%$ & $6.64 \%$ & $9.63 \%$ & $12.64 \%$ & $15.16 \%$ & $17.46 \%$ \\
\hline & & & Decentralized & $1.46 \%$ & $5.52 \%$ & $10.86 \%$ & $16.50 \%$ & $21.77 \%$ & $26.50 \%$ \\
\hline & & \multirow[t]{2}{*}{ MaxJob } & Centralized & $3.01 \%$ & $4.87 \%$ & $6.63 \%$ & $8.28 \%$ & $9.85 \%$ & $11.29 \%$ \\
\hline & & & Decentralized & $1.33 \%$ & $5.52 \%$ & $10.88 \%$ & $16.56 \%$ & $21.98 \%$ & $26.80 \%$ \\
\hline \multirow{8}{*}{$\begin{array}{r}\text { Mean } \\
\text { Tardiness }\end{array}$} & \multirow{4}{*}{ EDD } & \multirow{2}{*}{ EDD } & Centralized & 0.92 & 1.32 & 1.64 & 1.96 & 2.25 & 2.54 \\
\hline & & & Decentralized & 0.32 & 1.16 & 2.36 & 3.82 & 5.36 & 6.93 \\
\hline & & \multirow{2}{*}{ MaxJob } & Centralized & 0.82 & 1.35 & 1.79 & 2.24 & 2.64 & 3.04 \\
\hline & & & Decentralized & 0.29 & 1.10 & 2.28 & 3.70 & 5.34 & 7.06 \\
\hline & \multirow{4}{*}{ MODD } & \multirow{2}{*}{ EDD } & Centralized & 0.53 & 1.15 & 1.84 & 2.62 & 3.38 & 4.14 \\
\hline & & & Decentralized & 0.25 & 0.99 & 2.21 & 3.90 & 5.81 & 7.82 \\
\hline & & \multirow[t]{2}{*}{ MaxJob } & Centralized & 0.90 & 1.53 & 2.20 & 2.97 & 3.78 & 4.53 \\
\hline & & & Decentralized & 0.22 & 0.96 & 2.14 & 3.82 & 5.77 & 7.97 \\
\hline
\end{tabular}


Table 5: Performance Analysis - Number of Labor Transfers under Immediate Release (Pure Job Shop, Inter-arrival Rate Adjusted, and a Staffing Level of 4 Workers)

\begin{tabular}{|c|c|c|c|c|c|c|}
\hline \multirow{2}{*}{$\begin{array}{r}\text { Dispatching } \\
\text { Rule }\end{array}$} & \multirow{2}{*}{$\begin{array}{r}\text { Where } \\
\text { Rule }\end{array}$} & \multirow{2}{*}{$\begin{array}{r}\text { When } \\
\text { Rule }\end{array}$} & \multicolumn{4}{|c|}{ Labor transfer per 100 time units } \\
\hline & & & Where Rule ${ }^{1}$ & $\mathrm{Idll}^{2}$ & Total $^{3}$ & Foreman $^{4}$ \\
\hline \multirow{4}{*}{ EDD } & \multirow[t]{2}{*}{ EDD } & Centralized & 116.76 & 67.32 & 184.08 & 27.46 \\
\hline & & Decentralized & 0 & 73.14 & 73.14 & 27.31 \\
\hline & \multirow[t]{2}{*}{ MaxJob } & Centralized & 120.88 & 55.81 & 176.69 & 26.79 \\
\hline & & Decentralized & 0 & 71.28 & 71.28 & 27.03 \\
\hline \multirow{4}{*}{ MODD } & \multirow[t]{2}{*}{ EDD } & Centralized & 75.70 & 61.65 & 137.35 & 26.40 \\
\hline & & Decentralized & 0 & 69.68 & 69.68 & 26.58 \\
\hline & \multirow[t]{2}{*}{ MaxJob } & Centralized & 124.30 & 50.83 & 175.13 & 25.78 \\
\hline & & Decentralized & 0.00 & 67.83 & 67.83 & 26.38 \\
\hline $\begin{array}{l}\text { 1) Labor transfer fro } \\
\text { 2) Labor transfer fro } \\
\text { 3) Total number of } \\
\text { 4) Labor transfer to }\end{array}$ & ation d & & & & & \\
\hline
\end{tabular}

Table 6: Performance Analysis - Number of Labor Transfers per Station under Immediate Release, the Centralized When Rule, and EDD Dispatching (General Flow Shop, Inter-arrival Rate Adjusted, and a Staffing Level of 4 Workers)

\begin{tabular}{|c|c|c|c|c|c|c|c|}
\hline & \multirow{2}{*}{ Where Rule } & \multicolumn{6}{|c|}{ Labor transfers per 100 time units } \\
\hline & & Station 1 & Station 2 & Station 3 & Station 4 & Station 5 & Station 6 \\
\hline \multirow{2}{*}{$\begin{array}{l}\text { Labor transfer from a station } \\
\text { due to the Where Rule priority }\end{array}$} & EDD & 25.03 & 23.23 & 20.91 & 18.44 & 15.36 & 7.00 \\
\hline & MaxJob & 21.71 & 22.63 & 22.35 & 21.69 & 20.65 & 17.41 \\
\hline \multirow{2}{*}{$\begin{array}{l}\text { Labor transfer from a station } \\
\text { caused by the station being idle }\end{array}$} & EDD & 6.65 & 10.62 & 13.51 & 15.80 & 17.87 & 20.38 \\
\hline & MaxJob & 7.37 & 8.38 & 9.09 & 9.67 & 10.16 & 10.77 \\
\hline \multirow{2}{*}{$\begin{array}{r}\text { Labor transfer to the central } \\
\text { foreman }\end{array}$} & EDD & 4.44 & 5.03 & 5.06 & 4.91 & 4.82 & 4.70 \\
\hline & MaxJob & 4.90 & 4.57 & 4.48 & 4.42 & 4.37 & 4.28 \\
\hline
\end{tabular}



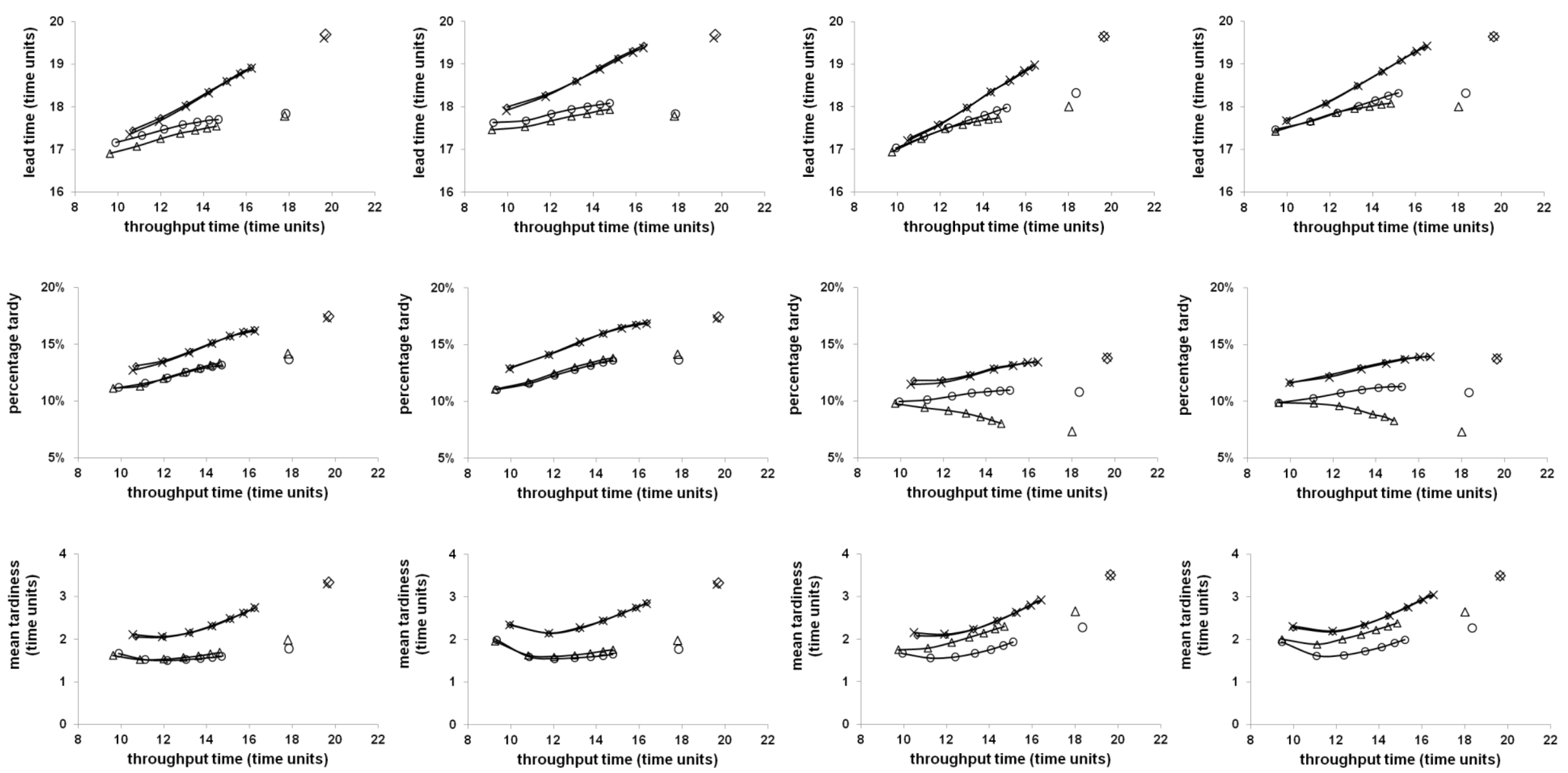

(a) Original \& EDD (Disp.)

(b) Refined \& EDD (Disp.)

(c) Original \& MODD (Disp.)

(d) Refined \& MODD (Disp.)

$$
\multimap \text { Centralized \& EDD } \triangle \text { Centralized \& MaxJob } \rightarrow \text { Decentralized \& EDD } \quad \text { *Decentralized \& MaxJob }
$$

Figure 1: Performance Results (Pure Job Shop, Inter-arrival Rate Adjusted, and a Staffing Level of 4 Workers) 

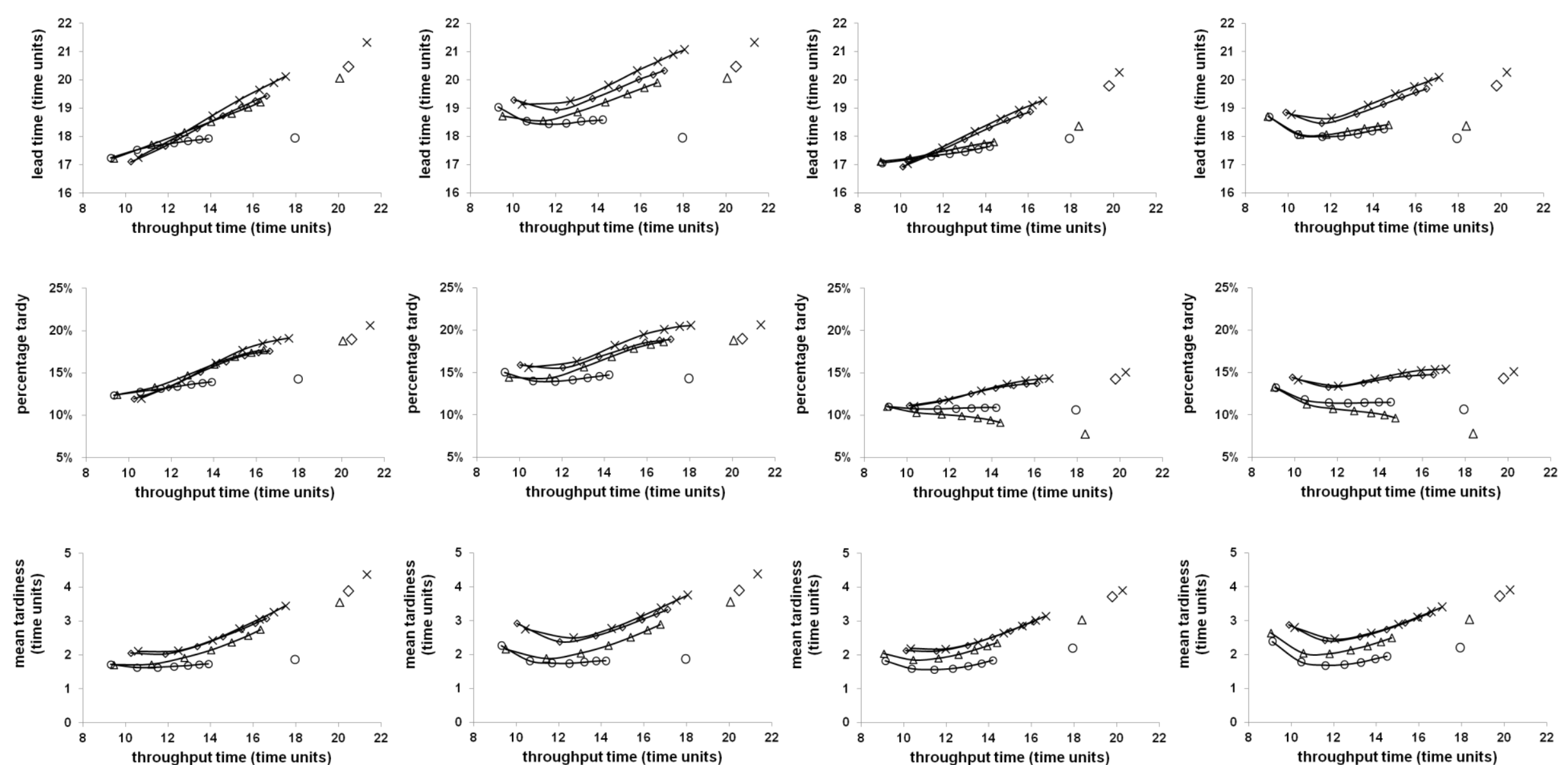

(a) Original \& EDD (Disp.)

(b) Refined \& EDD (Disp.)

(c) Original \& MODD (Disp.)

(d) Refined \& MODD (Disp.)

$$
\multimap \text { Centralized \& EDD } \triangle \text { Centralized \& MaxJob } \rightarrow \text { Decentralized \& EDD } \quad \text { *Decentralized \& MaxJob }
$$

Figure 2: Performance Results (General Flow Shop, Inter-arrival Rate Adjusted, and a Staffing Level of 4 Workers) 

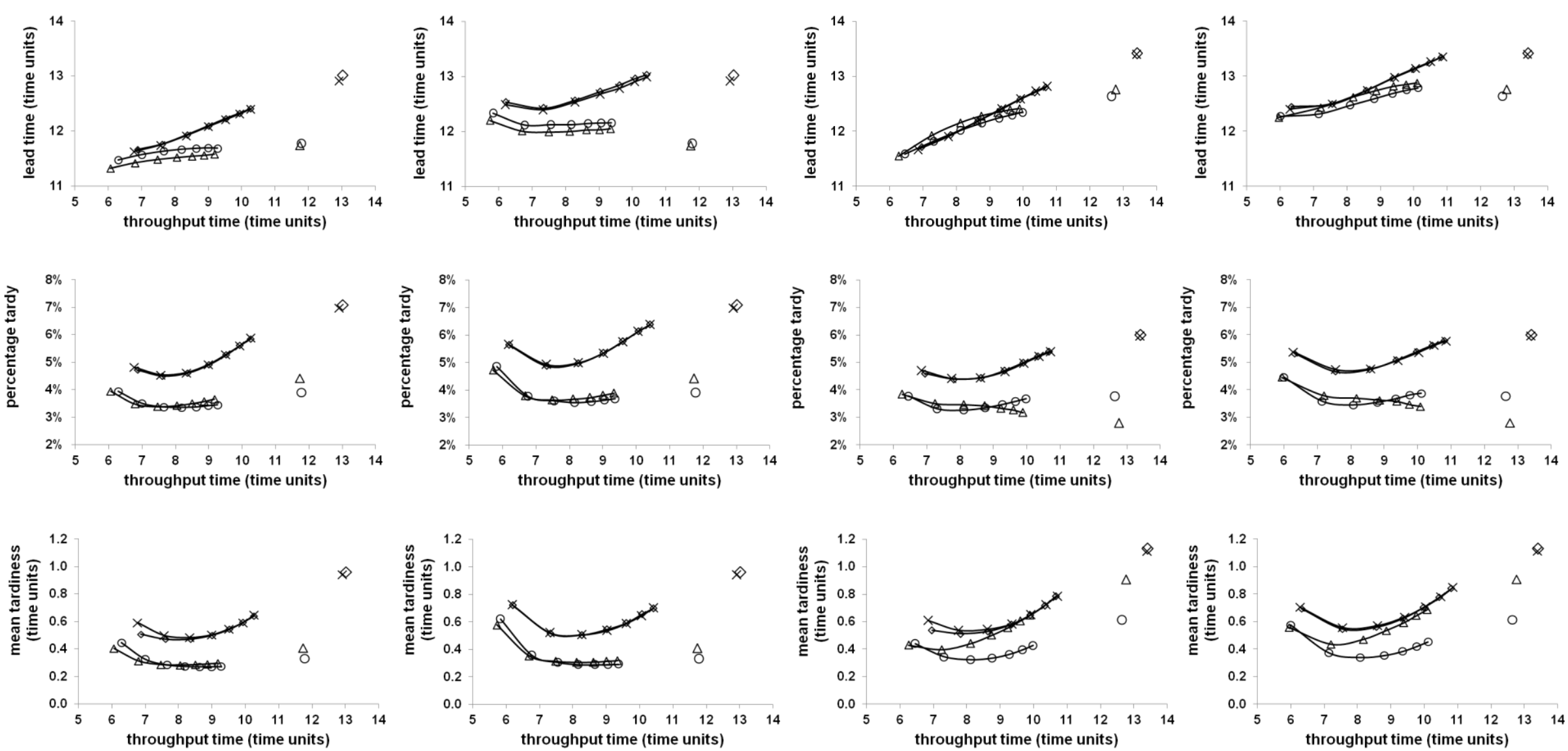

(a) Original \& EDD (Disp.)

(b) Refined \& EDD (Disp.)

(c) Original \& MODD (Disp.)

(d) Refined \& MODD (Disp.)

Figure 3: Performance Results (Pure Job Shop, Service Rate Adjusted, and a Staffing Level of 4 Workers) 


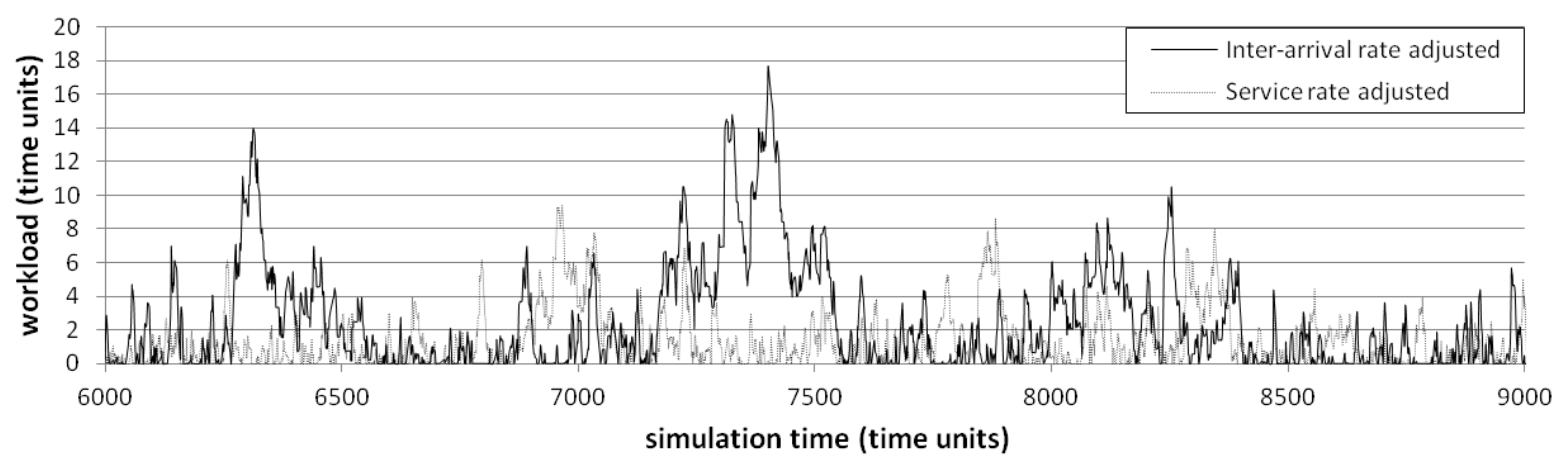

(a) Centralized When Rule, EDD Where Rule, and EDD Dispatching

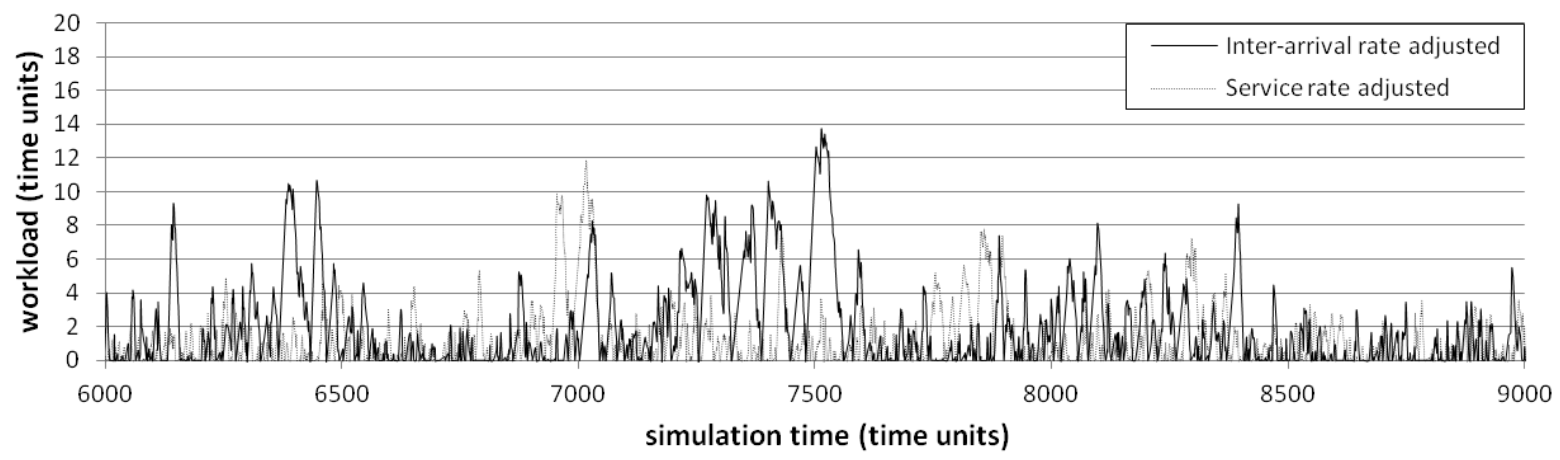

(b) Decentralized When Rule, EDD Where Rule, EDD Dispatching

Figure 4: Analysis of Workload Over Time under Immediate Release (Pure Job Shop and a Staffing Level of 4 Workers) 

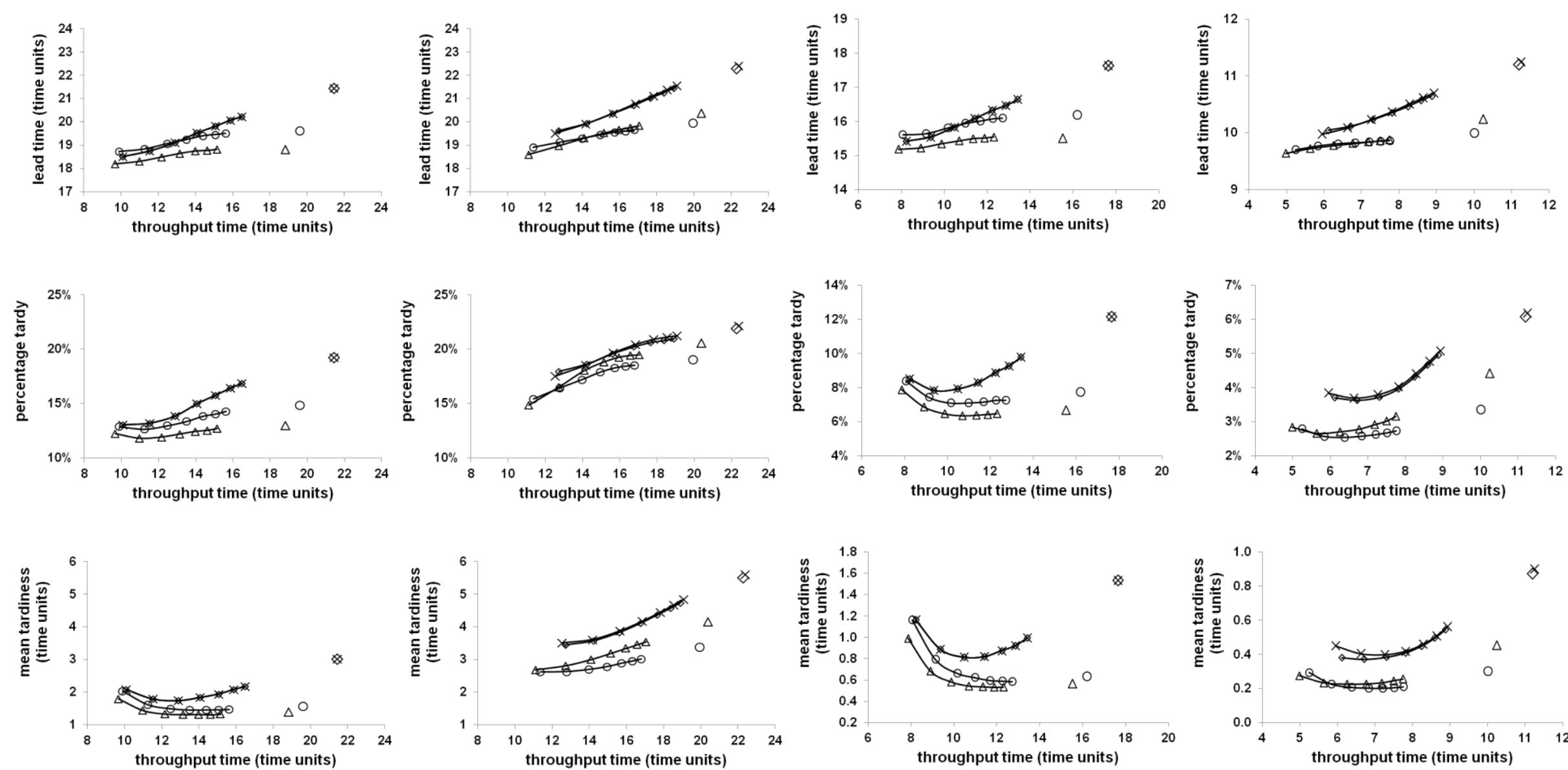

(a) 5 Workers \& Inter-Arrival

(b) 3 Workers \& Inter-Arrival

(c) 5 Workers \& Service Rate

(d) 3 Workers \& Service Rate

$$
\multimap \text { Centralized \& EDD } \quad \text { Centralized \& MaxJob } \rightarrow \text { Decentralized \& EDD } \quad \text { *Decentralized \& MaxJob }
$$

Figure 5: Performance Results for Different Adjustment Types and Staffing Levels (Pure Job Shop, Original Release, and EDD Dispatching) 